Article

\title{
Bioactive Compounds in Cornelian Cherry Vinegars
}

\author{
Joanna Kawa-Rygielska ${ }^{1, *}$, Kinga Adamenko ${ }^{1}$, Alicja Z. Kucharska ${ }^{2}$ (i) and Narcyz Piórecki ${ }^{3,4}$ \\ 1 Department of Fermentation and Cereals Technology, Faculty of Food Science, 51-630 Wrocław, Poland; \\ kinga.adamenko@upwr.edu.pl \\ 2 Department of Fruit, Vegetable and Plant Nutraceutical Technology, Faculty of Food Science, \\ Wroclaw University of Environmental and Life Sciences, 51-630 Wroław, Poland; \\ alicja.kucharska@upwr.edu.pl \\ 3 Arboretum and Institute of Physiography in Bolestraszyce, 37-700 Przemyśl, Poland; narcyz360@gmail.com \\ 4 Faculty of Physical Educaion, University of Rzeszów, 35-959 Rzeszów, Poland \\ * Correspondence: joanna.kawa-rygielska@upwr.edu.pl; Tel.: +48-71-320-7764
}

Received: 18 January 2018; Accepted: 7 February 2018; Published: 10 February 2018

\begin{abstract}
We analyzed the effect of Cornelian cherry varieties differing in fruit color ('Yantaryi'-yellow fruits, 'Koralovyi' - coral fruits, 'Podolski'—red fruits) and the production method on the physicochemical and antioxidative properties of Cornelian cherry vinegars, and on their content of iridoids and polyphenols. Acetic fermentation was conducted by two methods: I) single-stage (spontaneous) acetic fermentation, without inoculation with microorganisms, and II) two-stage fermentation in which the first stage involved the use of Saccharomyces bayanus-Safspirit fruit yeast for alcoholic fermentation, and the second one included spontaneous acetic fermentation. Acetic acid, glycerol, individual iridoids, phenolic acids, flavonols, and anthocyanins were quantified by a high-performance liquid chromatography (HPLC) method. The antioxidative activity was determined based on the following tests: 2,2-Diphenyl-2-picryl-hydrazyl ( $\left.\mathrm{DPPH}^{\bullet}\right)$, 2,2'-Azino-bis(3-ethylbenzo-thiazoline-6-sulfonic acid $\left(\mathrm{ABTS}^{\bullet+}\right)$, and ferric reducing antioxidant power (FRAP), while the total polyphenols content was determined using the Folin-Ciocialteu (F-C) reagent test. Both the Cornelian cherry variety and vinegar production method affected the antioxidative properties as well as concentrations of iridoids and polyphenols in the finished product. The concentration of total polyphenols (F-C) in vinegars ranged from 326.60 to $757.27 \mathrm{mg}$ gallic acids equivalents (GAE)/100 mL vinegar, whereas the antioxidative activity assayed with the $\mathrm{DPPH}^{\bullet}$ and FRAP methods was the highest in the vinegars produced from the coral and red varieties of Cornelian cherry with the two-stage method. Loganic acid predominated among the identified iridoids, reaching a concentration of $185.07 \mathrm{mg}$ loganic acid (LA)/100 $\mathrm{mL}$ in the vinegar produced in the two-stage fermentation from the coral-fruit variety. Caffeoylquinic acid derivatives were the main representatives among the identified phenolic compounds. The results of this study demonstrate Cornelian cherry vinegars to be rich sources of biologically-active iridoids and phenolic compounds with antioxidative properties.
\end{abstract}

Keywords: Cornelian cherry vinegar; fermentation; iridoids; polyphenols; antioxidative activity

\section{Introduction}

Vinegar is a popular food product manufactured in a two-stage fermentation process from a variety of raw materials, mostly including fruits. Many studies conducted so far have addressed fruit vinegar production via fermentation of juices from: apples, strawberries or pomegranates, and also from other untypical raw materials, like: Korean black raspberry or Litchi Chinensis fruit tree [1-4]. Ample investigations have demonstrated fruit vinegars to possess strong antioxidative properties and, thereby, to serve protective functions against adverse effects of pathogenic enteral flora, to exhibit 
anti-diabetic potential, to reduce blood concentration of lipids, to prevent arterial hypertension or to decrease the glycemic index of food products being sources of carbohydrates. Vinegars may as well be applied in the production of medicinal preparations being less straining to the body [5-9]. The strong antioxidative effect of vinegars is due to their bioactive compounds including: carotenoids, phytosterols and also phenolic compounds $[10,11]$ represented by, among others, flavonoids, tannins, anthocyanins or phenolic acids [12].

Fruit of Cornelian cherry (Cornus mas L.) contain a wide spectrum of compounds with antioxidative properties. They are used to produce juices, syrups and jams, but also-increasingly often-to prepare a fruit liquor (the so-called "dereniówka") which is an alcoholic distillate from these fruits. Previous studies have demonstrated both extracts and substances prepared from Cornelian cherry fruits to be rich in phenolics compounds and iridoids. The latter are representatives of cyclopentane monoterpenes with the main backbone constituted by a cyclopentane ring and pyran, which occur mainly in the glycosidic form. They display hypotensive, antibiotic, and anti-inflammatory effects $[13,14]$.

The quality of vinegars is determined by a few basic factors, the key ones of which include the raw materials they are made of, their method of acetylation, and their ageing procedure. Positive health outcomes of fruit vinegar consumption may be associated with transformations proceeding during their fermentation which lead to an increase in the content of their biologically-active compounds and to a change in their polyphenolic profile [14,15]. Earlier investigations have shown that contents of polyphenols in fruits and fruit products depend on both their pre-treatment and production methods and on conditions of their storage $[14,16,17]$. No works have been found in the available literature on the characteristics and properties of vinegars made from Cornelian cherry fruits. In this manuscript, we present results of analyses of the effect of the applied Cornelian cherry variety and fermentation method on the concentrations of iridoid and phenolic compounds and on the antioxidative properties of Cornelian cherry vinegars.

\section{Results}

\subsection{Dynamics of Alcoholic Fermentation}

Dynamics of the alcoholic fermentation process of juices from Cornelian cherry fruits of different coloration (yellow fruits $-\mathrm{Y}$, coral fruits $-\mathrm{C}$ and red fruits $-\mathrm{R}$ ) was determined based on changes in the weight of fermentation samples in time and expressed as the percentage loss of $\mathrm{CO}_{2}$. Results of these determinations for the single-stage fermentation are presented in Figure 1.

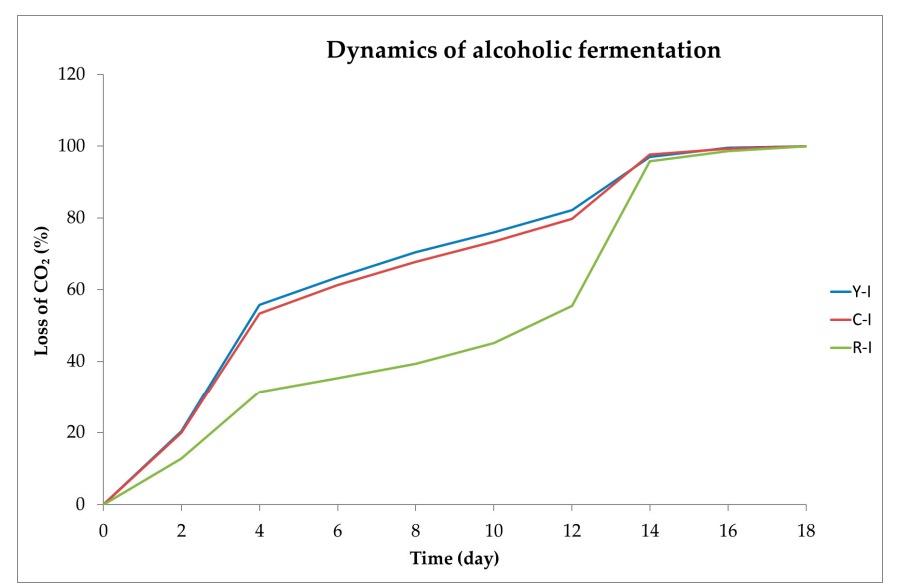

Figure 1. Dynamics of single-stage alcoholic fermentation (I) of juices made of three varieties of Cornelian cherry differing in fruit color: yellow $(\mathrm{Y})$, coral $(\mathrm{C})$, and red $(\mathrm{R})$, expressed as the percentage loss of carbon dioxide $\left(\mathrm{CO}_{2}\right)$ evolved within 18 days of the fermentation process. 
Dynamics of the single-step fermentation process of juices made of yellow (YI) and coral (CI) Cornelian cherries was similar and significantly higher than the fermentation dynamics of juice pressed from the red-fruit variety (RI). This observation was confirmed by the statistical analysis results. During the fermentation process, the volume of $\mathrm{CO}_{2}$ emitted from juice made of red fruit (RI) Cornelian cherry was by ca. $30 \%$ lower than in the other analyzed juices.

\subsection{Extract Content, $p H$ Value, and Concentrations of Acetic Acid, Alcohol and Glycerol}

Extract content and concentrations of acetic acid, glycerol and ethyl alcohol in the prepared vinegars and their $\mathrm{pH}$ values are presented in Table 1. Extract content ranged from 8.0 brix degrees $\left({ }^{\circ} \mathrm{Bx}\right)$ in YII sample to $12.8^{\circ} \mathrm{Bx}$ in CI sample, however these differences were statistically insignificant. The lowest $\mathrm{pH}$ value was measured in vinegars produced by the two-stage process from yellow (YII) and red (RII) fruits, whereas the highest one in the vinegar made of coral Cornelian cherry fruits (CI) in the single-stage fermentation process. Both the extract content and $\mathrm{pH}$ value were lower in the vinegars produced in the two-stage than in the single-stage process. Concentrations of acetic acid, glycerol, and ethyl alcohol in the analyzed vinegars were determined using high-performance liquid chromatography (HPLC). The concentration of acetic acid exceeded $40 \mathrm{~g} / \mathrm{L}$ vinegar in all samples. The highest acidity, indicated by $47.06 \mathrm{~g}$ acetic acid/L vinegar, was found for the vinegar produced from yellow-fruit Cornelian cherry in the YII, whereas the lowest one for the vinegar made of fruits of the same variety but in the single-stage fermentation (YI). In the case of yellow-fruit and red-fruit varieties, a higher concentration of acetic acid was determined in the vinegars produced in the two-stage than in the single-stage process of fermentation. The highest concentration of ethyl alcohol, i.e., $7.46 \mathrm{~g} / \mathrm{L}$ vinegar, was assayed in the vinegar produced from coral-fruit Cornelian cherry in the single-stage fermentation (CI). In contrast, no ethanol was found in the vinegars made of coral and red fruits in the two-stage process (CII and RII). The lowest concentration of ethanol, reaching $1.79 \mathrm{~g} / \mathrm{L}$ vinegar, was determined in the vinegar produced from coral-fruit Cornelian cherry in the single-stage fermentation (CI). Glycerol was found in all vinegar samples and its concentration ranged from 0.98 to $2.12 \mathrm{~g} / \mathrm{L}$ vinegar depending on the applied variety of Cornelian cherry and vinegar production method. Its highest concentration was determined in the vinegar made of red-fruit Cornelian cherry in the two-stage fermentation process.

Table 1. Extract content (brix degrees $\left({ }^{\circ} \mathrm{Bx}\right)$ ), $\mathrm{pH}$ value, and concentrations of acetic acid (g/L), ethyl alcohol $(\mathrm{g} / \mathrm{L})$ and glycerol $(\mathrm{g} / \mathrm{L})$ in vinegars produced from juices made of three varieties of Cornelian cherry differing in fruit color (Y, C, R) by using two different methods of fermentation (I, II).

\begin{tabular}{|c|c|c|c|c|c|c|}
\hline $\begin{array}{l}\text { Variety of } \\
\text { Cornelian } \\
\text { Cherry Fruit }\end{array}$ & $\begin{array}{l}\text { Method of } \\
\text { Fermentation }\end{array}$ & Extract $\left({ }^{\circ} \mathbf{B x}\right)$ & $\mathrm{pH}$ & $\begin{array}{l}\text { Glycerol } \\
\text { (g/L) }\end{array}$ & $\begin{array}{l}\text { Alcohol } \\
\text { (g/L) }\end{array}$ & $\begin{array}{l}\text { Acetic Acid } \\
\text { (g/L) }\end{array}$ \\
\hline \multirow{2}{*}{$Y^{1}$} & $I^{2}$ & $10.00^{\mathrm{a}} \pm 0.28$ & $2.81^{b} \pm 0.01$ & $0.99^{f} \pm 0.01$ & $1.79^{\mathrm{d}} \pm 0.01$ & $41.65^{\mathrm{f}} \pm 0.23$ \\
\hline & II & $8.00^{a} \pm 0.45$ & $2.76^{a} \pm 0.01$ & $1.20^{\mathrm{e}} \pm 0.04$ & $3.77^{b} \pm 0.01$ & $47.06^{\mathrm{a}} \pm 0.44$ \\
\hline \multirow{2}{*}{ C } & I & $12.80^{a} \pm 0.28$ & $2.90^{\mathrm{d}} \pm 0.01$ & $1.56^{\mathrm{d}} \pm 0.03$ & $7.46^{a} \pm 0.01$ & $42.30^{\mathrm{d}} \pm 0.24$ \\
\hline & II & $11.50^{a} \pm 0.71$ & $2.86^{\mathrm{c}} \pm 0.01$ & $1.72^{\mathrm{c}} \pm 0.03$ & 0.00 & $42.13^{\mathrm{e}} \pm 0.19$ \\
\hline \multirow{2}{*}{$\mathrm{R}$} & I & $11.40^{\mathrm{a}} \pm 0.57$ & $2.85^{c} \pm 0.00$ & $1.92^{b} \pm 0.03$ & $2.3^{c} \pm 0.01$ & $42.64^{c} \pm 0.76$ \\
\hline & II & $9.30^{\mathrm{a}} \pm 0.42$ & $2.76^{\mathrm{a}} \pm 0.01$ & $2.12^{\mathrm{a}} \pm 0.03$ & 0.0 & $45.38^{b} \pm 0.04$ \\
\hline
\end{tabular}

${ }^{1} \mathrm{Y}$, 'Jantarnyi' with yellow fruits; C, 'Koralovyi' with coral fruits; R, 'Podolski' with red fruits; ${ }^{2}$ I, single-step process of fermentation; II, two-step process of fermentation. ${ }^{3}$ Values are expressed as the mean $(n=3) \pm$ standard deviation. Mean values with different letters ( $a, b, c$, etc.) within the same column are statistically different ( $p$-value $<0.05)$.

\subsection{Color}

Values of color parameters $L^{*}, a^{*}$ and $b^{*}$ determined in vinegars produced from juices made of different varieties of Cornelian cherry are summarized in Table 2. Vinegars produced via single-stage acetic fermentation had a significantly higher value of color parameter $L^{*}$, indicative of sample lightness. The two-stage production process caused significant darkening of the vinegars. In turn, values of 
color parameters $a^{*}$ and $b^{*}$ were higher in the case of the vinegars produced in the two-stage process, compared to these manufactured via the single-stage fermentation.

Table 2. Values of color $L^{*}, a^{*}$ and $b^{*}$ in vinegars produced from juices made of three varieties of Cornelian cherry differing in fruit color $(\mathrm{Y}, \mathrm{C}, \mathrm{R})$ by using two different methods of fermentation (I, II).

\begin{tabular}{|c|c|c|c|c|}
\hline $\begin{array}{l}\text { Variety of Cornelian } \\
\text { Cherry Fruit }\end{array}$ & $\begin{array}{c}\text { Method of } \\
\text { Fermentation }\end{array}$ & $L^{*}$ & $a^{*}$ & $b^{*}$ \\
\hline \multirow{2}{*}{$Y^{1}$} & $\mathrm{I}^{2}$ & $70.73 \pm 0.00^{a, 3}$ & $10.98 \pm 0.01^{\mathrm{f}}$ & $48.22 \pm 0.04^{\mathrm{d}}$ \\
\hline & II & $64.46 \pm 0.01^{b}$ & $15.07 \pm 0.01^{\mathrm{e}}$ & $52.64 \pm 0.00^{c}$ \\
\hline \multirow{2}{*}{ C } & $\mathrm{I}$ & $49.85 \pm 0.00^{\mathrm{c}}$ & $36.05 \pm 0.00^{\mathrm{c}}$ & $59.97 \pm 0.02^{b}$ \\
\hline & II & $41.06 \pm 0.01^{\mathrm{d}}$ & $45.79 \pm 0.01^{b}$ & $61.01 \pm 0.13^{a}$ \\
\hline \multirow{2}{*}{$\mathrm{R}$} & I & $16.92 \pm 0.01^{\mathrm{e}}$ & $46.67 \pm 0.00^{a}$ & $9.39 \pm 0.10^{\mathrm{e}}$ \\
\hline & II & $5.72 \pm 0.26^{f}$ & $32.17 \pm 0.34^{d}$ & $28.59 \pm 0.40^{f}$ \\
\hline
\end{tabular}

${ }^{1} \mathrm{Y}$, 'Jantarnyi' with yellow fruits; C, 'Koralovyi' with coral fruits; R, 'Podolski' with red fruits; ${ }^{2} \mathrm{I}$, single-step process of fermentation; II, two-step process of fermentation; ${ }^{3}$ Values are expressed as the mean $(n=3) \pm$ standard deviation. Mean values with different letters $(a, b, c$, etc.) within the same column are statistically different $(p<0.05)$.

An exception was the value of $a^{*}$ parameter determined in the vinegar from red-fruit Cornelian cherry (RI). For example, values of color parameters $a^{*}$ and $b^{*}$ of the vinegar made of yellow-fruit variety in the single-stage process (YI) reached 10.98 and 48.22, respectively, whereas in the vinegar produced from the same variety of Cornelian cherry but in the two-stage process (YII) they accounted for 15.07 and 52.64, respectively.

\subsection{Concentration of Total Polyphenols and Antioxidative Activity}

Figure 2 presents the results of analyses of total polyphenols in vinegars from three varieties of Cornelian cherry differing in fruit color. The highest concentration of polyphenols (757.27 mg gallic acids equivalents (GAE)/100 mL vinegar) was determined in the vinegar produced from red-fruit Cornelian cherry in the two-stage fermentation process (RII). In contrast, their lowest concentration accounting for $326.60 \mathrm{mg} \mathrm{GAE} / 100 \mathrm{~mL}$ vinegar was found in the vinegar made of yellow-fruit variety in the single-stage process (YI). Results obtained demonstrate the total content of polyphenols in the analyzed vinegars to depend on vinegar production method and color of fruits, i.e., their variety. Regardless of Cornelian cherry variety the juice was made of, the total concentration of polyphenols was significantly higher in the vinegars produced in the two-stage fermentation process, compared to these manufactured in the single-stage process.

Figure 3 depicts the antioxidative activity of the analyzed vinegars determined with three methods: ferric reducing antioxidant power (FRAP), 2,2-Diphenyl-2-picryl-hydrazyl ( $\mathrm{DPPH}^{\bullet}$ ), and 2,2'-Azino-bis(3-ethylbenzo-thiazoline-6-sulfonic acid $\left(\mathrm{ABTS}^{\bullet+}\right)$. In the case of DPPH ${ }^{\bullet}$ and FRAP assays, the strongest antioxidative properties were shown for the samples produced via two-stage fermentation of juice from red-fruit (RII) and coral-fruit (CII) Cornelian cherry, i.e.,: $10.23 \mathrm{mmol}$ trolox (TE) $/ \mathrm{mL}$ and $9.97 \mathrm{mmol} \mathrm{TE} / \mathrm{mL}$ respectively when assayed with the $\mathrm{DPPH}^{\bullet}$ method, as well as 3.6 $\mathrm{mmol} \mathrm{TE} / \mathrm{mL}$ and $3.5 \mathrm{mmol} \mathrm{TE} / \mathrm{mL}$ respectively when assayed with the FRAP method. The lowest antioxidative activity determined with these methods was found for the vinegar produced from yellow-fruit variety in the single-stage acetic fermentation was demonstrated in vinegars produced in the two-stage compared to the single-stage fermentation. No similar tendency was observed in the case of the $\mathrm{ABTS}^{\bullet+}$ method. The activity against $\mathrm{ABTS}^{\bullet+}$ cation radical in the vinegars from coral-fruit and red-fruit varieties was higher when they were produced in the two-stage fermentation process, whereas in the case of vinegars made of yellow-fruit variety there were no significant differences between fermentation processes. There were linear correlations between total phenolic content and antioxidant activity. 


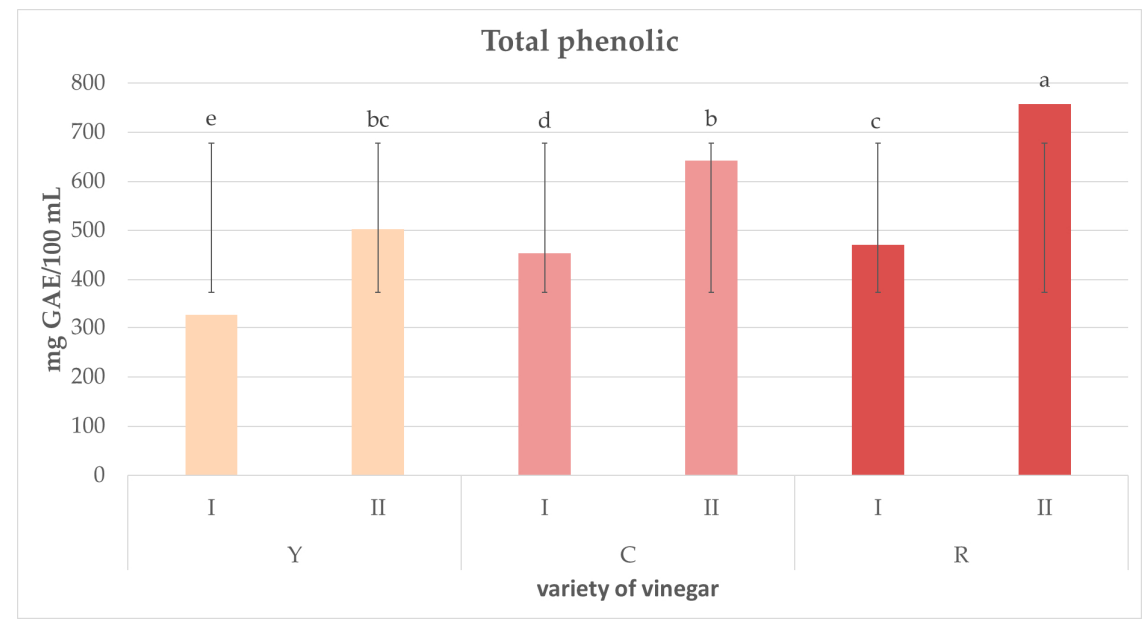

Figure 2. Total polyphenols concentration in vinegars produced from juices made of three varieties of Cornelian cherry differing in fruit color (Y, C, R) by using two different methods of fermentation (I, II). Values are expressed as the mean $(n=3) \pm$ standard deviation. Mean values with different letters $(\mathrm{a}, \mathrm{b}$, c, etc.) are statistically different ( $p$-value $<0.05)$.

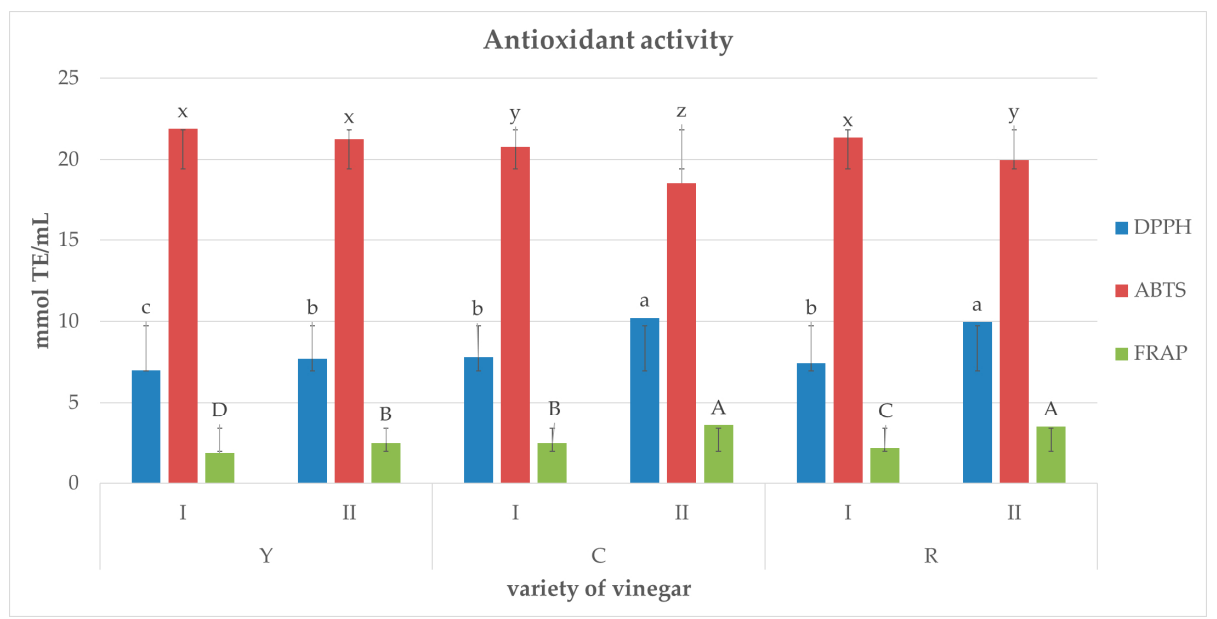

Figure 3. Antioxidative activity (FRAP, $\left.\mathrm{DPPH}^{\bullet}, \mathrm{ABTS}^{\bullet+}\right)$ of vinegars produced from juices made of three varieties of Cornelian cherry differing in fruit color $(Y, C, R)$ by using two different methods of fermentation (I, II). ${ }^{1}$ Values are expressed as the mean $(n=3) \pm$ standard deviation. Mean values with different letters: A, B, C, D (FRAP); a, b, c (DPPH $\left.{ }^{\bullet}\right) ; \mathrm{x}, \mathrm{y}, \mathrm{z}\left(\mathrm{ABTS}^{\bullet+}\right)$ are statistically different $(p<0.05)$.

\subsection{Quantitative Identification of Iridoids and Phenolic Compounds}

The vinegars produced from Cornelian cherry were found to contain compounds representative of monoterpenes (iridoids) and polyphenols (flavonols, anthocyanins, phenolic acids) (Table 3). The identified iridoids included: loganic acid (LA), cornuside (Co.) and a combination of sweroside (S) and loganin (Lo). Loganic acid was the predominating iridoid and its content in the analyzed vinegars ranged from 73 to $86 \%$ of total iridoids. In turn, Co. content constituted from 6 to $15 \%$ of total iridoids. The highest concentrations of LA and Co. were determined in the vinegar produced from the coral-fruit variety of Cornelian cherry in the two-stage fermentation (CII), i.e.,: 190.75 and 35.04 $\mathrm{mg} / 100 \mathrm{~mL}$ vinegar, respectively. The highest concentration of $\mathrm{S}+\mathrm{Lo}$, accounting for $34.72 \mathrm{mg} / 100 \mathrm{~mL}$ vinegar, was determined in the vinegar made of red-fruit variety in the two-stage process (RII). In the case of all identified iridoids, their higher concentrations were found in the vinegars produced in the two-stage process in which Saccharomyces bayanus-Safspirit fruit yeast were used for alcoholic 
fermentation, compared to the vinegars obtained via the single-stage fermentation. Compounds identified in the group of phenolic acids included derivatives of caffeoylquinic acid (CQA d) and $p$-coumaric acid ( $p$-CA d) and ellagic acid (EA). The predominating compound in this group was CQA d (9.64-24.18 mg/100 mL), followed by $p$-CA d (3.50-10.85 mg/100 mL), and EA (0.62-1.99 mg/100 mL).

The highest concentrations of $p$-CA d and CQA d reaching 24.18 and $10.85 \mathrm{mg} / 100 \mathrm{~mL}$ vinegar respectively, were determined in the vinegar produced from the coral-fruit variety in the two-stage fermentation process. In turn, the highest concentration of EA, i.e., $1.99 \mathrm{mg} / 100 \mathrm{~mL}$ vinegar, was found in the vinegar produced from the red-fruit variety in the two-stage process (RII). Among the identified flavonols, aromadendrin 7-O-glucoside (A 7-glu) was determined only in the vinegars from red-fruit variety of Cornelian cherry and its higher concentration accounting for $3.35 \mathrm{mg} / 100 \mathrm{~mL}$ vinegar was found in the sample produced in the two-stage process (RII). Kaempferol 3-O-galactoside (Kp 3-gal) was detected in the vinegars from the red-fruit and coral-fruit varieties of Cornelian cherry. Its concentration ranged from 0.10 to $2.53 \mathrm{mg} / 100 \mathrm{~mL}$ vinegar and was higher in the vinegars from the red-fruit variety. Other identified flavonols were: quercetin 3-O-galactoside ( $\mathrm{Q} 3$-gal) and quercetin 3-O-glucuronide ( $\mathrm{Q}$ 3-gluc). The highest $\mathrm{Q}$ 3-gal concentration was found in the vinegars from the red-fruit and coral-fruit varieties produced in the two-stage fermentation (RII, CII), and reached: $0.59 \mathrm{mg} / 100 \mathrm{~mL}$ of RII vinegar and $0.58 \mathrm{mg} / 100 \mathrm{~mL}$ of CII vinegar. In turn, the highest concentration of $Q$ 3-gluc was assayed in the sample of vinegar produced from coral-fruit Cornelian cherry in the two-stage process (CII). Its concentration in the analyzed vinegars ranged from $2.63 \mathrm{mg} / 100 \mathrm{~mL}$ in RI to $6.00 \mathrm{mg} / 100 \mathrm{~mL}$ in CII. Four anthocyanins were identified in the analyzed vinegars, but only in these produced from the red-fruit variety. Concentrations of all identified anthocyanins were higher in the samples obtained with the two-stage method (RII) and accounted for (in $100 \mathrm{~mL}$ vinegar): $0.75 \mathrm{mg}$ cyanidin 3-O-galactoside (Cy 3-gal), $0.41 \mathrm{mg}$ cyanidin 3-O-robinobioside (Cy 3-rob), $1.69 \mathrm{mg}$ pelargonidin 3-O-galactoside (Pg 3-gal), and $0.30 \mathrm{mg}$ pelargonidin 3-O-robinobioside (Pg 3-rob).

\section{Discussion}

Many researchers have recently paid special attention to fruits of Cornelian cherry (C. mas L.) [18-20], that are rich in biologically-active compounds, iridoids in particular, and thereby exhibit potential therapeutic properties [21-23].

Brix degrees are indicative of the percentage content of soluble substances, including mainly sugars, proteins and mineral salts. However, in such products as vinegars, they are used to determine the content of sugars only (with no consideration given to other soluble compounds). Factors which may determine the ${ }^{\circ} \mathrm{Bx}$ value of vinegars include: the culture of microorganisms used for the fermentation process and raw material used for vinegar production. The ${ }^{\circ} \mathrm{Bx}$ value is strictly linked with the fermentation process as sugar content decreases along with an increasing fermentation activity of microorganisms and may thus greatly vary [24]. The ${ }^{\circ} \mathrm{Bx}$ values determined in our study for Cornelian cherry vinegars were similar to extract content in fruit vinegars analyzed by other scientists $[24,25]$. The $\mathrm{pH}$ value of fruit vinegars is directly dependent on the raw materials they were made of [25]. Earlier investigations addressing the characteristics of the physicochemical properties of fruit vinegars have demonstrated their $\mathrm{pH}$ values to fit within the similar ranges [25-27].

Although the standard method for vinegar production is highly time-consuming, it enables the maximal consumption of substrates to produce appropriate amount of ethanol in the first stage of production and of acetic acid in the finished product [28]. The acidity of vinegars made of various raw materials should be not lesser than 4\% [29]. In turn, ethyl alcohol is a substrate of acetic fermentation and its concentration in vinegars is low [30]. Results obtained in our study are consistent with those reported by other authors about ethyl alcohol and acetic acid contents in fruit vinegars [25-28,31-33]. The alcoholic fermentation of sugars results in the generation of by-products, including glycerol. Earlier investigations have shown from 0.23 to $0.56 \%$ of glycerol in apple vinegars [28]. Compared to the above results, the concentration of glycerol in the analyzed Cornelian cherry vinegars was lower and ranged from 0.99 to $2.12 \mathrm{mg} / 100 \mathrm{~mL}$. 
Table 3. Iridoids and phenolic compounds content $(\mathrm{mg} / 100 \mathrm{~mL})$ in different vinegars from Cornus mas $\mathrm{L}$.

\begin{tabular}{|c|c|c|c|c|c|c|}
\hline Compound & RI & RII & CI & CII & YI & YII \\
\hline \multicolumn{7}{|c|}{ Iridoids } \\
\hline LA & $140.71 \pm 0.27^{\mathrm{e}, 1}$ & $178.46 \pm 0.73^{c}$ & $175.54 \pm 1.01^{\mathrm{c}}$ & $190.75 \pm 1.19^{a}$ & $158.38 \pm 0.52^{d}$ & $185.07 \pm 4.18^{b}$ \\
\hline S+Lo & $15.24 \pm 0.42^{\mathrm{e}}$ & $34.72 \pm 0.80^{a}$ & $19.83 \pm 0.23^{\mathrm{d}}$ & $27.38 \pm 0.97^{c}$ & $15.63 \pm 0.12^{\mathrm{f}}$ & $29.41 \pm 0.03^{b}$ \\
\hline Co. & $17.20 \pm 0.02 \mathrm{e}$ & $30.30 \pm 0.19^{c}$ & $22.49 \pm 0.04^{\mathrm{d}}$ & $35.04 \pm 0.39^{a}$ & $10.42 \pm 0.08^{\mathrm{f}}$ & $32.92 \pm 0.10^{b}$ \\
\hline \multicolumn{7}{|c|}{ Phenolic acids } \\
\hline EA & $0.87 \pm 0.02^{\mathrm{e}}$ & $1.99 \pm 0.02^{\mathrm{a}}$ & $1.13 \pm 0.02^{\mathrm{d}}$ & $1.69 \pm 0.01^{b}$ & $0.62 \pm 0.00^{f}$ & $1.52 \pm 0.01^{\mathrm{c}}$ \\
\hline Total CQA d & $10.47 \pm 0.00^{\mathrm{e}}$ & $19.66 \pm 0.24 b$ & $15.16 \pm 0.15^{\mathrm{d}}$ & $24.18 \pm 0.27^{\mathrm{a}}$ & $9.64 \pm 0.05^{f}$ & $17.10 \pm 0.07^{b}$ \\
\hline Total $p$-CA d & $3.50 \pm 0.00^{\mathrm{f}}$ & $6.70 \pm 0.43^{\mathrm{d}}$ & $7.39 \pm 0.01^{\mathrm{c}}$ & $10.85 \pm 0.02^{\mathrm{a}}$ & $4.89 \pm 0.06^{\mathrm{e}}$ & $9.21 \pm 0.01^{b}$ \\
\hline \multicolumn{7}{|c|}{ Anthocyanins } \\
\hline Cy 3-gal & $0.29 \pm 0.02^{b}$ & $0.75 \pm 0.03^{a}$ & nd & nd & nd & nd \\
\hline Cy 3-rob & $0.19 \pm 0.02^{b}$ & $0.41 \pm 0.00^{\mathrm{a}}$ & nd & nd & nd & nd \\
\hline Pg 3-gal & $0.65 \pm 0.04^{b}$ & $1.69 \pm 0.02^{\mathrm{a}}$ & nd & nd & nd & nd \\
\hline $\mathrm{Pg}$ 3-rob & $0.20 \pm 0.01^{b}$ & $0.30 \pm 0.20^{\mathrm{a}}$ & nd & nd & nd & nd \\
\hline \multicolumn{7}{|c|}{ Flavonols } \\
\hline A 7-glu & $1.80 \pm 0.02^{b}$ & $3.35 \pm 0.06^{\mathrm{a}}$ & nd & nd & nd & nd \\
\hline Q 3-gal & $0.32 \pm 0.02^{c}$ & $0.58 \pm 0.01^{\mathrm{a}}$ & $0.39 \pm 0.05^{b}$ & $0.59 \pm 0.01^{\mathrm{a}}$ & $0.19 \pm 0.00^{\mathrm{d}}$ & $0.34 \pm 0.00^{c}$ \\
\hline Q 3-gluc & $2.63 \pm 0.02^{\mathrm{e}}$ & $4.60 \pm 0.05^{b}$ & $4.07 \pm 0.05^{c}$ & $6.00 \pm 0.05^{\mathrm{a}}$ & $2.80 \pm 0.01^{\mathrm{d}}$ & $4.58 \pm 0.00^{b}$ \\
\hline Kp 3-gal & $1.38 \pm 0.00^{b}$ & $2.53 \pm 0.06^{\mathrm{a}}$ & $0.10 \pm 0.00^{c}$ & $0.17 \pm 0.01^{c}$ & nd & nd \\
\hline
\end{tabular}

LA, Loganic acid; S, Sweroside; Lo, Loganin; Co., Cornuside; EA, Ellagic acid; Total CQA d, total amount of caffeoylquinic acid derivatives; Total $p$-CA d, total amount of $p$-coumaric acid derivatives; Cy 3-gal, Cyjanidin 3-O-galactoside; Cy 3-rob, Cyjanidin 3-O-robinobioside; Pg 3-gal, Pelargonidine 3-O-galactoside; Pg 3-rob, Pelargonidine 3-O-robinobioside; A 7-glu, Aromadendrin 7-O-glucoside; Q 3-gal, Quercetin 3-O-galactoside; Q 3-gluc, Quercetin 3-O-glucuronide; Kp 3-gal, Kaempferol 3-O-galactoside. ${ }^{1}$ Values are expressed as the mean ( $n=3$ ) \pm standard deviation. Mean values with different letters (a, b, c, etc.) within the same row are statistically different ( $p$-value $<0.05)$; nd, not detected. 
The color of vinegars is an important factor which affects purchase decisions made by consumers [34]. The study addressing color analysis of vinegars produced from fruits of, among others, hawthorn, grape, sour cherry, pomegranate and strawberries has shown that values of color parameters depend on fruit species [25].

The Cornelian cherry vinegars analyzed in our study differed in the concentration of total polyphenolics which ranged from 326.60 to $757.27 \mathrm{mg}$ GAE/100 mL. No works have been found in the available literature that would report such a high concentration of total polyphenolics in fruit vinegars. Earlier studies have shown total polyphenolics content to reach $255 \mathrm{mg}$ GAE/ $100 \mathrm{~mL}$ in balsamic vinegar [26], 222.88 mg GAE/100 mL in apple vinegar [25], $161 \mathrm{mg}$ GAE/100 mL in strawberry vinegar [9], and $138 \mathrm{mg} \mathrm{GAE/100} \mathrm{mL} \mathrm{in} \mathrm{citrus} \mathrm{fruit} \mathrm{vinegar} \mathrm{[35].} \mathrm{Significantly} \mathrm{lower} \mathrm{concentrations}$ of these compounds were determined in vinegars made of grape-26 mg GAE/100 mL [36] or hawthorn-28 mg GAE/100 mL [26]. Considerable differences observed between results obtained in our study and findings of other authors may be due to the fact that the concentration of polyphenolics in vinegars depends most of all on the type of raw material as well as on their production process including: duration and conditions of fermentation and conditions of ageing [36,37]. The content of total polyphenolics in fruits of Cornelian cherry expressed as gallic acid equivalents ranges from 209 to $811 \mathrm{mg} \mathrm{GAE} / 100 \mathrm{~g}$ [38-40]. In other fruits, it is lower compared to Cornelian cherry and accounts for: 72.27-290 mg GAE/100 $\mathrm{g}$ in grapes [41-43], 398-670.9 mg GAE/100 $\mathrm{g}$ in berries [43-45], 109.72-268.35 $\mathrm{mg} \mathrm{GAE} / 100 \mathrm{~g}$ in goji berries [46,47], or 260-2556 mg GAE/100 $\mathrm{g}$ in chokeberry fruits [34,48-50]. Samples subjected to ethanolic fermentation with the use of $S$. bayanus-Safspirit fruit yeast were characterized by higher concentrations of polyphenolics, which may result from the fact that alcoholic fermentation stabilizes the antioxidative potential of plant materials relatively well, which is due to the low redox potential during anaerobic fermentation of worts.

The total content of polyphenolics is associated with antioxidative properties. Hence, the antioxidative activity determined with FRAP and $\mathrm{DPPH}^{\bullet}$ assays was higher in the vinegars produced in the two-stage fermentation process. Alongside results of total polyphenolics concentration, the strongest antioxidative properties were determined in the vinegars made of red-fruit and coral-fruit varieties of Cornelian cherry. The analyzed Cornelian cherry vinegars had a higher antioxidative activity compared to fruit vinegars obtained by other researchers. It may be due to the fact that Cornelian cherry fruits are characterized by a higher content of polyphenolics compared to other fruit materials used for vinegar production, as the total content of polyphenolics affects the antioxidative activity. Earlier investigations addressing antioxidative properties of fruit vinegars were conducted using the FRAP method $[26,51,52]$, the DPPH ${ }^{\bullet}$ method $[26,53-55]$ and also the ABTS ${ }^{\bullet+}$ method $[26,27,51-55]$, which shown that the antioxidant activity of vinegars depends on the type of fruit.

The analyzed Cornelian cherry vinegars were characterized by various concentrations of bioactive compounds. The predominating group of these compounds were iridoids whose total concentration ranged from 173.3 to $253.2 \mathrm{mg} / 100 \mathrm{~mL}$. Iridoids occur only in a few fruits, including Cornelian cherry and Japanese cornel, blue honeysuckle, lingonberry or cranberry $[13,14,56,57]$, hence compounds belonging to this group have not been detected in fruit vinegars studied so far. The presence of iridoids in consumed food products is important as they affect their taste and biological properties. Iridoids with an open cyclopentane ring between C-7 and C-8 atom of carbon, referred to as secoiridoids, are responsible for the bitter taste, like e.g., oleuropein in olives. No distinct bitterness may be perceived in Cornelian cherry fruits in spite of the fact that their iridoids include open-ring compounds like e.g., cornuside and secologanin [58]. This is also the case with Cornelian cherry products like jams and liqueurs [13] or vinegars, like these analyzed in our study. The presence of iridoids in food products increases their biological value, because they exhibit, i.e., anti-inflammatory, antimicrobial, antidiabetic, anti-atherosclerotic, cyto-, hepato-, neuro- and renal-protective, antiplatelet, and antiglaucomic activities $[21-23,59]$. The quality and biological properties of plant food products are also affected by polyphenolics, which have especially great impact on their color, astringency, flavor, and antioxidative 
activity [60]. The predominating phenolic compounds in the analyzed vinegars were phenolic acids. Compared to Cornelian cherry fruits [13], the fruit vinegar was characterized by richer quantitative and qualitative composition of phenolic acids, which suggests that these acids may be released from high-molecular structures during fermentation. High concentrations of such phenolic acids as: gallic acid, $p$-coumaric acid, caffeic acid, and caffeoylquinic acid, were determined in fruit vinegars also by other authors $[26,51,55]$. The major flavonoids of Cornelian cherry fruits include anthocyanins, followed by flavonols. Anthocyanins are highly unstable pigments and occur only in strongly colored varieties of Cornelian cherry, hence their trace amounts were identified only in the vinegar from the red-fruit variety. In turn, flavonols were determined in all analyzed vinegars, regardless of variety, and their qualitative composition was comparable with the composition of fruits. The concentration of flavonols in vinegars is affected by their content in fruits. Kelebek et al. determined concentrations of flavonols in apple and grape vinegars at $2.46 \mathrm{mg} / 100 \mathrm{~mL}$ and $0.07 \mathrm{mg} / 100 \mathrm{~mL}$, respectively [55]. The analysis of our results demonstrates that the content of flavonols is influenced not only by the species but also by the variety of fruits, because the highest concentration of these compounds was determined in vinegars from red fruits and the lowest one in vinegars from yellow fruits of Cornelian cherry.

\section{Materials and Methods}

\subsection{Reagents and Standards}

1,1-Diphenyl-2-picrylhydrazyl radical $\left(\mathrm{DPPH}^{\bullet}\right)$; 6-hydroxy-2,5,7,8-tetramethylchroman-2carboxylic acid (Trolox); 2,4,6-tri(2-pyridyl)-s-triazine (TPTZ), dimethyl sulfoxide (DMSO), $\mathrm{FeCl}_{3}$, acetonitrile, formic acid, and $\mathrm{S}$, sulfuric acid and sodium hydroxide were acquired from Sigma-Aldrich (Steinheim, Germany). Acetic acid was obtained from Chempur (PiekarySląskie, Poland). Acetonitrile for liquid chromatography-mass spectrometry was purchased from POCh (Gliwice, Poland). Loganic acid, and Lo, $p$-CA, 5-O-caffeoylquinic acid (5-CQA, chlorogenic acid), quercetin 3-O-glucoside, kaempferol-3-O-glucoside (Kp 3-gluc), cyanidin 3-O-glucoside (Cy 3-glc) were purchased from Extrasynthese (Lyon Nord, France). All reagents were of analytical grade.

\subsection{Biological Material}

The biological material used for the ethanolic fermentation of Cornelian cherry fruit were S. bayanus-Safspirit fruit yeast from the Fermentis company (Lesaffre, Marcq-en-Barœul, France). Before being inoculated, dried yeast obtained from the producer were rehydrated in distilled water at a temperature of $25^{\circ} \mathrm{C}$ for $30 \mathrm{~min}$.

\subsection{Raw Material}

Cornelian cherry fruits (C. mas L.) from 3 cultivars: 'Florianka' (red color), 'Yantarnyi' (yellow color) and 'Koralovyi' (coral color) were harvested in the Arboretum in Bolestraszyce, near Przemyśl, Poland. The plant materials were authenticated by Prof. Jakub Dolatowski (Arboretum and Institute of Physiography in Bolestraszyce, Przemyśl, Poland), and the adequate voucher specimens ('Yantarnyi'—BDPA 14131; 'Koralovyi'—BDPA 14136; 'Podolski'—BDPA 10462) have been deposited at the Herbariums of Arboretum in Bolestraszyce, Poland. Fruits were harvested in September 2016, and immediately frozen at $-20^{\circ} \mathrm{C}$.

\subsection{Preparation of Fermentation Samples}

All fruits of Cornelian cherry were pressed through a laboratory press to obtain juices that were further used in the study. Resultant juices were poured into fermentation flasks. In the first experimental variant involving the spontaneous fermentation process, the flasks were prepared for fermentation by covering them with a sterile gauze to control the access of oxygen. In turn, in the second experimental variant which included two-stages, first of which consisted in alcoholic fermentation, 
the juices were inoculated with S. bayanus - Safspirit fruit yeast in the amount of $0.5 \mathrm{~g} / \mathrm{L}$. The flasks were tightly closed with fermentation bungs to produce anaerobic conditions. In all experimental variants, $\mathrm{pH}$ was adjusted to 4.5 using $0.1 \mathrm{M} \mathrm{NaOH}$ before alcoholic fermentation.

\subsection{Fermentation}

Table 4 presents symbols used to describe experimental variants.

Table 4. Description and symbols of vinegar production methods and Cornelian cherry fruits used in the experiment.

\begin{tabular}{|c|c|c|}
\hline Symbol & Description & \\
\hline I & $\begin{array}{l}\text { Single-stage (spontaneous) alcoholic-acetic } \\
\text { fermentation under controlled aerobic conditions. }\end{array}$ & \\
\hline II & $\begin{array}{l}\text { Two-stage fermentation including first alcoholic } \\
\text { fermentation with the use of Saccharomyces } \\
\text { bayanus-Safspirit fruit yeast, followed by } \\
\text { spontaneous acetic fermentation. }\end{array}$ & Vinegar production method \\
\hline $\mathrm{Y}$ & Yellow ('Yantarnyi' variety with yellow fruits) & \multirow{3}{*}{$\begin{array}{l}\text { Cornelian cherry variety/fruit } \\
\text { color }\end{array}$} \\
\hline $\mathrm{C}$ & Coral ('Koralovyi' variety with coral fruits) & \\
\hline $\mathrm{R}$ & Red ('Podolski' variety with red fruits) & \\
\hline
\end{tabular}

The samples prepared for single-stage fermentation (YI, CI, RI) were placed on a 358 A Type laboratory shaker (Elpin Plus, Lubawa, Poland) and mixed with the frequency of 50 cycles $/ \mathrm{min}$ at a temperature of $25{ }^{\circ} \mathrm{C}$ for 60 days. In turn, the samples intended for the two-stage process of vinegar production (YII, CII, RII) were firstly subjected to alcoholic fermentation with S. bayanus-Safspirit fruit yeast under anaerobic conditions, at a temperature of $25^{\circ} \mathrm{C}$ for 18 days. Afterwards, the fermented juices were decanted from above the yeast precipitate and prepared for the next stage like the samples intended for the spontaneous fermentation. The second-stage of fermentation lasted 42 days.

\subsection{Analytical Methods}

\subsubsection{Extract, pH, Acetic Acid, Ethanol and Glycerol Content}

Extract $\left({ }^{\circ} \mathrm{Bx}\right)$ in vinegars was tested at the temperature of $20{ }^{\circ} \mathrm{C}$ with the use of a Densito $30 \mathrm{PX}$ densimeter (Mettler Toledo, Columbus, $\mathrm{OH}, \mathrm{USA}$ ) whereas $\mathrm{pH}$ was measured with the use of a Mettler Toledo MP 240 pH-meter.

Acetic acid, ethanol and glycerol were determined by means of HPLC [61]. Degassed and centrifuged ( 2675 centrifugal force (RCF), $6000 \mathrm{rpm}, 10 \mathrm{~min}$ ) samples were diluted with ultra-pure water in the volumetric ratio of 1:7; then filtered through a nylon syringe filter with pore size of $0.22 \mu \mathrm{m}$ into chromatographic vials. The samples were analyzed using a Prominence liquid chromatography system (Shimadzu Corp., Kyoto, Japan) equipped in a Rezed ROA-Organic Acid H+ column $(300 \times 4.6 \mathrm{~mm})$ from Phenomenex (Torrance, CA, USA). The following parameters of measurements were applied: injection volume $20 \mu \mathrm{L}$, elution temperature $60{ }^{\circ} \mathrm{C}$, flow rate $0.6 \mathrm{~mL} / \mathrm{min}$, mobile phase $0.005 \mathrm{M}$ $\mathrm{H}_{2} \mathrm{SO}_{4}$, and thermostat refractometric detector at $50{ }^{\circ} \mathrm{C}$. Concentrations of acetic acid, ethyl alcohol and glycerol were determined based on a five-point calibration curve integrated in Chromax 10.0 software by Pol-Lab (Wilkowice, Poland).

\subsubsection{Instrumental Analysis of Color}

The color of the vinegars (reflectance values: $L^{*}, a^{*}$ and $b^{*}$ ) was measured using a Color Quest XE HunterLab (Reston, VA, USA) spectrophotometer. Each sample was placed in a glass cuvette, and its color $L^{*}, a^{*}, b^{*}$ values were determined using Illuminant D65 and an observer angle of $10^{\circ} . L^{*}$ denotes 
'lightness', and its values range from 0 to 100 ( 0 for ideal black, and 100 for ideal white). A positive value of $a^{*}$ indicates 'red color', a negative value of $a^{*}$ indicates 'green color', a positive value of $b^{*}$ indicates 'yellow color', and a negative value of $b^{*}$ indicates 'blue color'.

\subsubsection{Phenolic Compound Analysis}

Total polyphenol content and antioxidant activity were analyzed with the use of a UV-2401 PC spectrophotometer (Shimadzu Corp).

\section{Determination of Total Polyphenols Content}

The total polyphenols content of the vinegars was determined using the Folin-Ciocalteu (F-C) sprectophotometric method [62]. Vinegar samples and F-C reagent were pipetted into cuvettes. After $3 \mathrm{~min}, 1 \mathrm{~mL}$ of a $20 \%$ aqueous solution of sodium carbonate $\left(\mathrm{Na}_{2} \mathrm{CO}_{3}\right)$ and $2 \mathrm{~mL}$ of distilled water were added. The absorbance was measured at $7650 \mathrm{~nm}$ after $1 \mathrm{~h}$, and the results were expressed as $\mathrm{mg}$ of GAE per $100 \mathrm{~mL}$ of vinegar. Data were expressed as the mean value for three measurements. Calibration curves of gallic acid in the range $0.30-9.00 \mathrm{mg}$ GAE/ $\mathrm{L}$ were used to read off the results.

Free-Radical-Scavenging Ability by the Use of a DPPH Radical

The antiradical activity was determined using a $\mathrm{DPPH}^{\bullet}$ assay [63]. $0.1 \mathrm{~mL}$ samples of vinegars were mixed with $2 \mathrm{~mL}$ of $0.04 \mathrm{mmol} / \mathrm{L} \mathrm{DPPH}^{\bullet}$ in methanol and $0.4 \mathrm{~mL} \mathrm{of} \mathrm{H}_{2} \mathrm{O}$. After $10 \mathrm{~min}$ of incubation at room temperature, the absorbance was measured with a spectrophotometer at $517 \mathrm{~nm}$ using disposable polystyrene cuvettes. A calibration curve was prepared with Trolox solution $\left(0.05 \times 10^{-1} \mathrm{mmol} / \mathrm{L}\right)$. The data were expressed as Trolox equivalent (TE) of antioxidative capacity per hundred milliliters of the vinegar (TEAC, $\mathrm{mmol} \mathrm{TE} / \mathrm{mL}$ ). All measurements were performed in triplicate. Calibration curves, in the range $2-10 \mu \mathrm{mol} \mathrm{TE} / \mathrm{L}$, showing good linearity $\left(r^{2} \geq 0.998\right)$.

Free-Radical-Scavenging Ability by the Use of a ABTS Radical Cation.

The antioxidative activity of vinegars was determined using the $\mathrm{ABTS}^{\bullet+}$ assay [64]. $0.03 \mathrm{~mL}$ samples of vinegar were mixed with $3 \mathrm{~mL}$ of $\mathrm{ABTS}^{\bullet+}$ solution with measured absorption of 0.700 at a wavelength of $734 \mathrm{~nm}$. After 6 min the absorbance of samples was measured. Each sample was tested in triplicate. The data were expressed as mmol Trolox equivalent of antioxidative capacity per 100 milliliters of the vinegar (mmol TE/mL). Calibration curves, in the range 1.70-21.70 $\mu \mathrm{mol} \mathrm{TE} / \mathrm{L}$, showed good linearity $\left(r^{2} \geq 0.999\right)$.

Ferric Reducing/Antioxidant Power (FRAP) Assay

The FRAP is based on the reduction of ferric 2,4,6-tris(2-pyridyl)-1,3,5-triazine [Fe(III)-TPTZ] to the ferrous complex at low $\mathrm{pH}$, followed by spectrophotometric analysis [65]. Briefly, the reagent was prepared by mixing $10 \mathrm{mmol}$ 2,4,6-Tris(2-pyridyl)-s-triazine (TPTZ)/L reagent with $20 \mathrm{mmol} / \mathrm{L}$ ferric chloride in acetate buffer $(\mathrm{pH}$ 3.6). Quantitative analyses were performed by the external standard method using ferrous sulfate $\left(2 \times 10^{-1} \mathrm{mmol} / \mathrm{L}\right)$ as the reference standard and correlating the absorbance $(\lambda 593 \mathrm{~nm})$ with the concentration. $0.2 \mathrm{~mL}$ samples of vinegar were mixed in polystyrene cuvettes with $0.8 \mathrm{~mL}$ of distilled water and $3 \mathrm{~mL}$ of ferric complex. The results were calculated and expressed as millimoles of Trolox per milliliter of the vinegar. The absorbance was read in disposable polystyrene cuvettes using a spectrophotometer. All measurements were performed in triplicate. Calibration curves, in the range 1.25-12.50 $\mu \mathrm{mol} \mathrm{TE} / \mathrm{L}$, showed good linearity $\left(r^{2} \geq 0.998\right)$.

\section{Quantification of Iridoids and Polyphenols by HPLC-PDA}

The high-performance liquid chromatography photodiode array detection method (HPLC-PDA) analysis was previously described by Kucharska et al. [30]. It was performed using a Dionex (Germering, Germany) system equipped with an Ultimate 3000 model diode array detector, LPG-3400A 
quaternary pump, EWPS-3000SI autosampler, TCC-3000SD thermostated column compartment, and controlled by the Chromeleon v.6.8 software (Thermo Scientific Dionex, Sunnyvale, CA, USA). A Cadenza Imtakt C5-C18 column (75 4.6 mm, $5 \mathrm{~m}$ ) was used (Imtakt, Kyoto, Japan). The mobile phase was composed of solvent A (4.5\% aq. formic acid, $v / v)$ and solvent B (100\% acetonitrile). The elution system was as follows: 0-1 min 5\% B in C, $20 \mathrm{~min} 25 \%$ B in A, $21 \mathrm{~min} \mathrm{100 \%} \mathrm{B,} 26 \mathrm{~min} \mathrm{100 \%} \mathrm{B,} 27 \mathrm{~min}$ $5 \% \mathrm{~B}$ in $\mathrm{A}$. The flow rate of the mobile phase was $1.0 \mathrm{~mL} / \mathrm{min}$ and the injection volume was $20 \mu \mathrm{L}$. The column was operated at $30^{\circ} \mathrm{C}$. Iridoids were detected at $245 \mathrm{~nm}$, phenolic acids and their derivatives at $320 \mathrm{~nm}$, ellagic acid at $254 \mathrm{~nm}$, flavonols at $360 \mathrm{~nm}$, and anthocyanins at $520 \mathrm{~nm}$. Loganic acid and Co. were expressed as LA, Lo and S as Lo, caffeoylquinic acids derivatives as 5-O-caffeoylquinic acid, $p$-cumaric acid derivatives as $p$-cumaric acid, quercetin derivatives and aromadendrin 7-O-glucoside as quercetin 3-O-glucoside, kaempferol 3-O-galactoside as kaempferol 3-O-glucoside, anthocyanins as cyanidin 3-O-glucoside. The results were expressed as $\mathrm{mg}$ per $100 \mathrm{~mL}$ vinegar.

\subsection{Statistics}

Mean deviations are shown on graphs. Selected data were processed using the Statistica 13.5 software (StatSoft, Tulsa, OK, USA), a one-way analysis of variance (ANOVA) at a significance level of $\alpha=0.05$. Differences between means were tested with the Duncan test $(p$-value $<0.05)$.

\section{Conclusions}

The study demonstrated the feasibility of using the analyzed varieties of Cornelian cherry for the production of fruit vinegars with potential health properties. The highest concentration of biologically-active compounds was determined in the vinegar made of red-fruit variety. Cornelian cherry juices allow one to obtain vinegars rich in iridoids. In addition, this study proved the fermentation method to have a significant impact on the final concentration of active compounds in the finished product. The use of S. bayanus - Safspirit fruit yeast to carry out alcoholic fermentation significantly increased the content of biologically-active compounds in the final products. Cornelian cherry vinegars, as a natural food product, can be a good source of antioxidants in the human diet.

Acknowledgments: Publication supported by the Wroclaw Centre of Biotechnology, Leading National Research Centre programme (KNOW) for years 2014-2018.

Author Contributions: J.K.-R., K.A., A.K.; conceived and designed the experiments; performed the experiments; analyzed the data; contributed reagents, materials and analytical tools; wrote the paper; N.P.; contributed raw materials.

Conflicts of Interest: The authors declare no conflict of interest.

\section{References}

1. Nazıroğlu, M.; Güler, M.; Özgül, C.; Saydam, G.; Küçükayaz, M.; Sözbir, E. Apple cider vinegar modulates serum lipid profile, erythrocyte, kidney, and liver membrane oxidative stress in ovariectomized mice fed high cholesterol. J. Membr. Biol. 2014, 247, 667-673. [CrossRef] [PubMed]

2. Park, J.E.; Kim, J.Y.; Kim, J.; Kim, Y.J.; Kim, M.J.; Kwon, S.W.; Kwon, O. Pomegranate vinegar beverage reduces visceral fat accumulation in association with AMPK activation in overweight women: A double-blind, randomized, and placebo-controlled trial. J. Funct. Foods 2014, 8, 274-281. [CrossRef]

3. Yang, J.F.; Yang, C.H.; Liang, M.T.; Gao, Z.J.; Wu, Y.W.; Chuang, L.Y. Chemical composition, antioxidant, and antibacterial activity of wood vinegar from Litchi chinensis. Molecules 2016, 21, 1150. [CrossRef] [PubMed]

4. Lee, M.Y.; Kim, H.Y.; Singh, D.; Yeo, S.H.; Baek, S.Y.; Park, Y.K.; Lee, C.H. Metabolite profiling reveals the effect of dietary Rubuscoreanus vinegar on ovariectomy-induced osteoporosis in a rat model. Molecules 2016, 21, 149. [CrossRef] [PubMed]

5. Chen, G.L.; Zheng, F.J.; Sun, J.; Li, Z.C.; Lin, B.; Li, Y.R. Production and characteristics of high quality vinegar from sugarcane juice. Sugar Tech 2015, 17, 89-93. [CrossRef] 
6. Chou, C.H.; Liu, C.W.; Yang, D.J.; Wu, Y.H.S.; Chen, Y.C. Amino acid, mineral, and polyphenolic profiles of black vinegar, and its lipid lowering and antioxidant effects in vivo. Food Chem. 2015, 168, 63-69. [CrossRef] [PubMed]

7. Dou, Z.; Li, K.; Wang, P.; Cao, L. Effect of wine and vinegar processing of Rhizoma corydalis on the tissue distribution of tetrahydropalmatine, protopine and dehydrocorydaline in rats. Molecules 2012, 17, 951-970. [CrossRef] [PubMed]

8. Wu, H.; Waldbauer, K.; Tang, L.; Xie, L.; McKinnon, R.; Zehl, M.; Yang, H.; Xu, H.; Kopp, B. Influence of vinegar and wine processing on the alkaloid content and composition of the traditional Chinese medicine Corydalis Rhizoma (Yanhusuo). Molecules 2014, 19, 11487-11504. [CrossRef] [PubMed]

9. Ho, C.W.; Lazim, A.M.; Fazry, S.; Zaki, U.K.H.H.; Lim, S.J. Varieties, production, composition and health benefits of vinegars: A review. Food Chem. 2017, 221, 1621-1630. [CrossRef] [PubMed]

10. Charoenkiatkul, S.; Thiyajai, P.; Judprasong, K. Nutrients and bioactive compounds in popular and indigenous durian (Duriozibethinusmurr.). Food Chem. 2016, 193, 181-186. [CrossRef] [PubMed]

11. Masino, F.; Chinnici, F.; Bendini, A.; Montevecchi, G.; Antonelli, A. A study on relationships among chemical, physical, and qualitative assessment in traditional balsamic vinegar. Food Chem. 2008, 106, 90-95. [CrossRef]

12. Slobodníková, L.; Fialová, S.; Rendeková, K.; Kováč, J.; Mučaji, P. Antibiofilm activity of plant polyphenols. Molecules 2016, 21, 1717. [CrossRef] [PubMed]

13. Kucharska, A.Z. Active Compounds of Cornelian Cherry Fruit (Cornus mas L.); Publishing House of University of Wroclaw: Wroclaw, Poland, 2012.

14. Kucharska, A.Z.; Sokół-Łętowska, A.; Oszmiański, J.; Piórecki, N.; Fecka, I. Iridoids, Phenolic compounds and antioxidant activity of edible Honeysuckle berries (Loniceracaerulea var. Kamtschatica Sevast.). Molecules 2017, 22, 405. [CrossRef] [PubMed]

15. Zulkawi, N.; Ng, K.H.; Zamberi, R.; Yeap, S.K.; Satharasinghe, D.; Jaganath, I.B.; Jamaluddin, A.B.; Tan, S.W.; Ho, W.Y.; Alitheen, N.B.; Long, K. In vitro characterization and in vivo toxicity, antioxidant and immunomodulatory effect of fermented foods; Xeniji ${ }^{\mathrm{TM}}$. BMC Complement. Altern. Med. 2017, 17, 344-356. [CrossRef] [PubMed]

16. Moldovan, B.; David, L. Influence of temperature and preserving agents on the stability of cornelian cherries anthocyanins. Molecules 2014, 19, 8177-8188. [CrossRef] [PubMed]

17. Oszmiański, J.; Lachowicz, S. Effect of the production of dried fruits and juice from chokeberry (Aroniamelanocarpa L.) on the content and antioxidative activity of bioactive compounds. Molecules 2016, 21, 1098. [CrossRef] [PubMed]

18. Cosmulescu, S.; Trandafir, I.; Nour, V. Phenolic acids and flavonoids profiles of extracts from edible wild fruits and their antioxidant properties. Int. J. Food Prop. 2017, 20, 3124-3134. [CrossRef]

19. Bozdogan, A. Viscosity and physicochemical properties of cornelian cherry (Cornus mas L.) concentrate. J. Food Meas. Charact. 2017, 11, 1326-1332. [CrossRef]

20. Dinda, B.; Kyriakopoulos, A.M.; Dinda, S.; Zoumpourlis, V.; Thomaidis, N.S.; Velegraki, A.; Markopoulos, C.; Dinda, M. Cornus mas L. (cornelian cherry), an important European and Asian traditional food and medicine: Ethnomedicine, phytochemistry and pharmacology for its commercial utilization in drug industry. J. Ethnopharmacol. 2016, 193, 670-690. [CrossRef] [PubMed]

21. Sozański, T.; Kucharska, A.Z.; Rapak, A.; Szumny, D.; Trocha, M.; Merwid-Ląd, A.; Dzimira, S.; Piasecki, T.; Piórecki, N.; Magdalan, J.; et al. Iridoid-loganic acid versus anthocyanins from the Cornus mas fruits (cornelian cherry): Common and different effects on diet-induced atherosclerosis, PPARs expression and inflammation. Atherosclerosis 2016, 254, 151-160. [CrossRef] [PubMed]

22. Sozański, T.; Kucharska, A.Z.; Szumny, A.; Magdalan, J.; Bielska, K.; Merwid-Ląd, A.; Woźniak, A.; Dzimira, S.; Piórecki, N.; Trocha, M. The protective effect of the Cornus mas fruits (cornelian cherry) on hypertriglyceridemia and atherosclerosis through PPAR $\alpha$ activation in hypercholesterolemic rabbits. Phytomedicine 2014, 21, 1774-1784. [CrossRef] [PubMed]

23. Sozański, T.; Kucharska, A.Z.; Szumny, A.; Magdalan, J.; Merwid-Ląd, A.; Nowak, B.; Piórecki, N.; Dzimira, S.; Jodkowska, A.; Szelagg, A.; et al. Cornelian cherry consumption increases the L-arginine/ADMA ratio, lowers ADMA and SDMA levels in the plasma, and enhances the aorta glutathione level in rabbits fed a high-cholesterol diet. J. Funct. Foods 2017, 34, 189-196. [CrossRef] 
24. Sáiz-Abajo, M.J.; Gonzáles-Sáiz, J.M.; Pizarro, C. Classification of wine and alcohol vinegar samples based on near-infrared spectroscopy. Feasibility study on the detection of adulterated vinegar samples. J. Agric. Food Chem. 2004, 52, 7711-7719. [CrossRef] [PubMed]

25. Ozturk, I.; Caliskan, O.Z.N.U.R.; Tornuk, F.; Ozcan, N.; Yalcin, H.; Baslar, M.; Sagdic, O. Antioxidant, antimicrobial, mineral, volatile, physicochemical and microbiological characteristics of traditional home-made Turkish vinegars. LWT-Food Sci. Technol. 2015, 63, 144-151. [CrossRef]

26. Bakir, S.; Devecioglu, D.; Kayacan, S.; Toydemir, G.; Karbancioglu-Guler, F.; Capanoglu, E. Investigating the antioxidant and antimicrobial activities of different vinegars. Eur. Food Res. Technol. 2017, 243, 2083-2094. [CrossRef]

27. Budak, N.H. Bioactive components of Prunus avium L. black gold (red cherry) and Prunus avium L. stark gold (white cherry) juices, wines and vinegars. J. Food Sci. Technol. 2017, 54, 62-70. [CrossRef] [PubMed]

28. Lea, A.G.H. Cider Vinegar. Processed Apple Products; Van Nostrand Reinhold: New York, NY, USA, 1989; pp. 279-301.

29. Compliance Policy Guides CPG, Sec. 525.825 Vinegar, Definitions: Adulteration with Vinegar Eels. Silver Spring, MD, USA: Food and Drug Administration (FDA). 2015. Available online: http:/ /www.fda.gov/ICECI/ ComplianceManuals/CompliancePolicyGuidanceManual/ucm074471.htm (accessed on 9 September 2017).

30. Saichana, N.; Matsushita, K.; Adachi, O.; Frebort, I.; Frebortova, J. Acetic acid bacteria: A group of bacteria with versatile biotechnological applications. Biotechnol. Adv. 2015, 33, 1260-1271. [CrossRef] [PubMed]

31. Zou, B.; Wu, J.; Yu, Y.; Xiao, G.; Xu, Y. Evolution of the antioxidant capacity and phenolic contents of persimmon during fermentation. Food Sci. Biotechnol. 2017, 26, 563-571. [CrossRef]

32. Dias, D.R.; Silva, M.S.; de Souza, A.C.; Magalhães-Guedes, K.T.; de Rezende Ribeiro, F.S.; Schwan, R.F. Vinegar production from Jabuticaba (Myrciaria jaboticaba) fruit using immobilized acetic acid bacteria. Food Technol. Biotechnol. 2016, 54, 351-359. [CrossRef] [PubMed]

33. Roda, A.; Lucini, L.; Torchio, F.; Dordoni, R.; De Faveri, D.M.; Lambri, M. Metabolite profiling and volatiles of pineapple wine and vinegar obtained from pineapple waste. Food Chem. 2017, 229, 734-742. [CrossRef] [PubMed]

34. Benvenuti, S.; Pellati, F.; Melegari, M.; Bertelli, D. Polyphenols, anthocyanins, ascorbic acid, and radical scavenging activity of Rubus, Ribes, and Aronia. J. Food Sci. 2004, 69, 164-169. [CrossRef]

35. Chen, Y.; Huang, Y.; Bai, Y.; Fu, C.; Zhou, M.; Gao, B.; Donsheng, L.; Hu, Y.; Xu, N. Effects of mixed cultures of Saccharomyces cerevisiae and Lactobacillus plantarum in alcoholic fermentation on the physicochemical and sensory properties of citrus vinegar. LWT-Food Sci. Technol. 2017, 84, 753-763. [CrossRef]

36. Natera, R.; Castro, R.; Valme-Garcia-Moreno, M.D.; Hernandez, M.J.; Garcia-Barroso, C. Chemometric studies of vinegars from different raw materials and processes of production. J. Agric. Food Chem. 2003, 51, 3345-3351. [CrossRef] [PubMed]

37. Păltinean, R.; Mocan, A.; Vlase, L.; Gheldiu, A.M.; Crișan, G.; Ielciu, I.; Voștinaru, O.; Crișan, O. Evaluation of polyphenolic ontent, antioxidant and diuretic activities of six fumaria species. Molecules 2017, $22,639$. [CrossRef] [PubMed]

38. Dragović-Uzelac, V.; Levaj, B.; Bursać, D.; Pedisić, S.; Radojčić, I.; Biško, A. Total phenolics and antioxidant capacity assays of selected fruits. Agric. Conspec. Sci. 2007, 72, 279-284.

39. Tural, S.; Koca, I. Physico-chemical and antioxidant properties of cornelian cherry fruits (Cornus mas L.) grow in Turkey. Sci. Hortic. 2008, 116, 362-366. [CrossRef]

40. Rop, O.; Mlcek, J.; Kramarova, D.; Jurikova, T. Selected cultivars of cornelian cherry (Cornus mas L.) as a new food source for human nutrition. Afr. J. Biotechnol. 2010, 9, 1205-1210.

41. Özcan, M.M.; Al Juhaimi, F.; Gülcü, M.; Uslu, N.; Geçgel, Ü.; Ghafoor, K.; Dursun, N. Effect of harvest time on physico-chemical properties and bioactive compounds of pulp and seeds of grape varieties. J. Food Sci. Technol. 2017, 54, 2230-2240. [CrossRef] [PubMed]

42. Obreque-Slier, E.; Pena-Neira, A.; Lopez-Solis, R.; Zamora-Marin, F.; Ricardo-da Silva, J.M.; Laureano, O. Comparative study of the phenolic composition of seeds and skins from Carménère and Cabernet Sauvignon grape varieties (Vitis vinifera L.) during ripening. J. Agric. Food Chem. 2010, 58, 3591-3599. [CrossRef] [PubMed]

43. Marinova, D.; Ribarova, F.; Atanassova, M. Total phenolics and total flavonoids in Bulgarian fruits and vegetables. J. Chem. Technol. Metall. 2005, 40, 255-260. 
44. Ren, M.; Wang, X.; Tian, C.; Li, X.; Zhang, B.; Song, X.; Zhang, J. Characterization of organic acids and phenolic compounds of cereal vinegars and fruit vinegars in China. J. Food Process. Preserv. 2017, 41, 1-8. [CrossRef]

45. Bunea, A.; Rugina, D.O.; Pintea, A.M.; Sconta, Z.; Bunea, C.I.; Socaciu, C. Comparative polyphenolic content and antioxidant activities of some wild and cultivated blueberries from Romania. Not. Bot. Horti Agrobot. Cluj Napoca 2011, 39, 70-76.

46. Donno, D.; Beccaro, G.L.; Mellano, M.G.; Cerutti, A.K.; Bounous, G. Goji berry fruit (Lycium spp.): Antioxidant compound fingerprint and bioactivity evaluation. J. Funct. Foods 2015, 18, 1070-1085. [CrossRef]

47. Jatoi, M.A.; Jurić, S.; Vidrih, R.; Vinceković, M.; Vuković, M.; Jemrić, T. The effects of postharvest application of lecithin to improve storage potential and quality of fresh goji (Lycium barbarum L.) berries. Food Chem. 2017, 230, 241-249. [CrossRef] [PubMed]

48. Jakobek, L.; Šeruga, M.; Medvidović-Kosanović, M.; Novak, I. Antioxidant activity and polyphenols of Aronia in comparison to other berry species. Agric. Conspec. Sci. 2007, 72, 301-306.

49. Rop, O.; Mlcek, J.; Jurikova, T.; Valsikova, M.; Sochor, J.; Reznicek, V.; Kramarova, D. Phenolic content, antioxidant capacity, radical oxygen species scavenging and lipid peroxidation inhibiting activities of extracts of five black chokeberry (Aronia melanocarpa (michx.) elliot) cultivars. J. Med. Plants Res. 2010, 22, 2432-2437.

50. Zheng, W.; Wang, S.Y. Oxygen radical absorbing capacity of phenolics in blueberries, cranberries, chokeberries, and lingonberries. J. Agric. Food Chem. 2003, 51, 502-509. [CrossRef] [PubMed]

51. Bakir, S.; Toydemir, G.; Boyacioglu, D.; Beekwilder, J.; Capanoglu, E. Fruit antioxidants during vinegar processing: Changes in content and in vitro bio-accessibility. Int. J. Mol. Sci. 2016, 17, 1658. [CrossRef] [PubMed]

52. Pastoriza, S.; Rufián-Henares, J.A. Contribution of melanoidins to the antioxidant capacity of the Spanish diet. Food Chem. 2004, 164, 438-445. [CrossRef] [PubMed]

53. Kalaycıŏglu, Z.; Erim, F.B. Total phenolic contents, antioxidant activities, and bioactive ingredients of juices from pomegranate cultivars worldwide. Food Chem. 2017, 221, 496-507. [CrossRef] [PubMed]

54. Ubeda, C.; Callejón, R.M.; Hidalgo, C.; Torija, M.J.; Troncoso, A.M.; Morales, M.L. Employment of different processes for the production of strawberry vinegars: Effects on antioxidant activity, total phenols and monomeric anthocyanins. LWT-Food Sci. Technol. 2013, 52, 139-145. [CrossRef]

55. Kelebek, H.; Kadiroğlu, P.; Demircan, N.B.; Selli, S. Screening of bioactive components in grape and apple vinegars: Antioxidant and antimicrobial potential. J. Inst. Brew. 2017, 123, 407-416. [CrossRef]

56. Turner, A.; Chen, S.N.; Nikolic, D.; van Breemen, R.; Farnsworth, N.R.; Pauli, G.F. Coumaroyl iridoids and a depside from cranberry (Vaccinium macrocarpon). J. Nat. Prod. 2007, 70, 253-258. [CrossRef] [PubMed]

57. Jenen, H.D.; Krogfelt, K.A.; Cornett, C.; Hansen, S.H.; Christensen, S.B. Hydrophilic carboxylic acids and iridoid glycosides in the juice of American and European cranberries (Vaccinium macrocarpon and $V$. oxycoccos), lingonberries (V. Vitis-idaea), and blueberries (V. myrtillus). J. Agric. Food Chem. 2002, 50, 6871-6874. [CrossRef]

58. Deng, S.; West, B.J.; Jensen, C.J. UPLC-TOF-MS characterization and identification of bioactive iridoids in Cornus mas fruit. J. Anal. Methods Chem. 2013, 2013, 710972. [CrossRef] [PubMed]

59. Wei, S.; Chi, H.; Kodama, H.; Chen, G. Anti-inflammatory effect of three iridoids in human neutrophils. Nat. Prod. Res. 2013, 27, 911-915. [CrossRef] [PubMed]

60. Rice-Evans, C.A.; Miller, N.; Paganga, G. Antioxidant properties of phenolic compounds. Trends Plant Sci. 1997, 2, 152-159. [CrossRef]

61. Pietrzak, W.; Kawa-Rygielska, J. Simultaneous saccharification and ethanol fermentation of waste wheat-rye bread at very high solids loading: Effect of enzymatic liquefaction conditions. Fuel 2015, 147, $236-242$. [CrossRef]

62. Prior, R.L.; Wu, X.; Schaich, K. Standardized methods for the determination of antioxidant capacity and phenolics in foods and dietary supplements. J. Agric. Food Chem. 2005, 53, 4290-4302. [CrossRef] [PubMed]

63. Yen, G.-C.; Chen, H.-Y. Antioxidant activity of varous tea extracts in relation to their antimutagenicity. J. Agric. Food Chem. 1995, 43, 27-32. [CrossRef]

64. Re, R.; Pellegrini, N.; Proteggente, A.; Pannala, A.; Yang, M.; Rice-Evans, C. Antioxidant activity applying an improved ABTS radical cation decolorization assay. Free Radic. Biol. Med. 1999, 26, 1231-1237. [CrossRef] 
65. Benzie, I.F.; Strain, J.J. The ferric reducing ability of plasma (FRAP) as a measure of "antioxidant power": The FRAP assay. Anal. Biochem. 1996, 239, 70-76. [CrossRef] [PubMed]

Sample Availability: Samples of the compounds are available from the authors. 